\title{
Characterization of Biofilm Formation by Xylella fastidiosa In Vitro
}

\author{
L. L. R. Marques and H. Ceri, Biofilm Research Group, University of Calgary, Calgary, AB, Canada, T2K 1N4; \\ G. P. Manfio, CPQBA/Universidade Estadual de Campinas, Campinas, SP, Brazil; D. M. Reid, Department of Bio- \\ logical Sciences, University of Calgary, Calgary, AB, Canada; and M. E. Olson, Biofilm Research Group, Univer- \\ sity of Calgary, Calgary, AB, Canada
}

\begin{abstract}
Marques, L. L. R., Ceri, H., Manfio, G. P., Reid, D. M., and Olson, M. E. 2002. Characterization of biofilm formation by Xylella fastidiosa in vitro. Plant Dis. 86:633-638.

Xylella fastidiosa colonizes the xylem of various host plants, causing economically important diseases such as Pierce's disease in grapevine and citrus variegated chlorosis (CVC) in sweet oranges. The aggregative nature of this bacterium has been extensively documented in the plant xylem and the insect's foregut. Structured communities of microbial aggregates enclosed in a self-produced polymeric matrix and attached to a surface are defined as biofilms. In this study, we characterized biofilm formation by $X$. fastidiosa through the use of a novel in vitro assay for studying biofilm growth in a potential mimic system of what might occur in planta. We used wood, a xylem rich material, as a surface for bacterial attachment and biofilm formation, under shear force. We demonstrated that $X$. fastidiosa strains isolated from various hosts formed biofilm on wood in this in vitro assay. Different biofilm morphology was detected, which seems to vary according to the strain tested and microenvironmental conditions analyzed. We observed that strains from different hosts could be grouped according to three parameters: biofilm morphology, the ability to form clumps in liquid culture, and the ability to attach to glass surfaces. We hypothesize that biofilm formation is likely a major virulence factor in diseases related to $X$. fastidiosa, bringing a new perspective for disease treatment.
\end{abstract}

For many years, microorganisms have been mostly described as planktonic organisms (free-living suspensions of single cells). In the past two decades, the increasing advances in microbiological techniques have highlighted that many microbial species grow predominantly in biofilms in natural environments (8).

Biofilms can be defined as structured communities of sessile microbial aggregates, enclosed in a self-produced polymeric matrix, attached to an inert or living surface (8). The U.S. Centers for Disease Control and Prevention (CDC) has estimated that biofilms cause $65 \%$ of infections in the developed world (7), including cystic fibrosis pneumonia and dental caries, as well as many implant- and medical device-associated infections (9). Biofilms also pose a constant challenge in industrial settings, being sources of recurrent contamination of products and process lines and causing biocorrosion and clogging of filters and pipelines (8). The treatment of all these problems is difficult, due to the remarkably reduced susceptibility of biofilms to antibiotics and biocides $(2,3,8)$.

Corresponding author: Merle E. Olson

E-mail: molson@ucalgary.ca

Accepted for publication 4 February 2002.

Publication no. D-2002-0329-03R

(C) 2002 The American Phytopathological Society
A few studies associating microbial biofilms and plants have been reported, mostly describing large biofilms growing on leaf, root, hypocotyl, and cotyledon surfaces $(14,15,24,25)$. The occurrence of quorum-sensing gene regulation (i.e., dependent upon bacterial population density) among plant-associated bacteria further indicates the likelihood of biofilm formation by these organisms (28). Likewise, there are several reports of plant diseases presenting symptoms related to clogging of xylem vessels by bacterial aggregates and exopolysaccharide (EPS) $(6,17,21)$.

Infections caused by Xylella fastidiosa are classical examples of xylem blocking by bacterial aggregates and exopolymeric substance deposition, in conjunction with plant tyloses and gum $(17,35)$. This bacterium is a fastidious xylem-limited plant pathogen transmitted via grafting and by xylem-feeding insects in nurseries and in the field. $X$. fastidiosa infections have enormous impact in a range of economically important crops, including Pierce's disease (PD) in grapevine and citrus variegated chlorosis (CVC) in sweet oranges. In addition, it has been related to alfalfa dwarf and peach leaf scorch, among other diseases in trees such as almond, elm, oak, oleander, peach, plum, maple, and sycamore $(17,30,36)$.

The major symptoms of $X$. fastidiosa diseases, including leaf marginal necrosis, chlorosis, leaf abscission, dieback, delayed growth, and decline of vigor, are related to water-stress and limited xylem flow, due to occlusion of the xylem by bacterial aggregates, gums, and tyloses (17) and an exopolymeric matrix that is likely to contain EPS (32). The formation of large aggregates by $X$. fastidiosa strains has been extensively reported (17,30). Moreover, direct support of $X$. fastidiosa aggregative nature comes from scanning electron microscopy (SEM) analyses of infected grape xylem $(34,35)$ and insects (1).

Based on this evidence, we hypothesize that $X$. fastidiosa is predominantly capable of a biofilm mode of growth both in vitro and in vivo, in plant and insect hosts, and is likely to cause biofilm infections in plants.

In order to evaluate biofilm formation by $X$. fastidiosa strains, we developed a novel in vitro model for biofilm growth using wood, a xylem rich material, as a surface for bacterial attachment. We demonstrate, for the first time, in vitro biofilm formation by $X$. fastidiosa strains isolated from various plant hosts.

\section{MATERIAL AND METHODS}

Bacterial strains and growth conditions. Bacterial strains and sources: CCT 6746 (=ATCC 35870), almond strain (Prunus dulcis, California); CCT 5598, CCT 5641, CCT 5643, and CCT 5674, citrus (Citrus sp., SP, Brazil); CCT 6739 and CCT 6740, coffee (Coffea arabica, SP, Brazil); CCT 6748 (=ATCC 35873), elm (Ulmus sp., Washington, DC); CCT 6068, CCT $6752^{\mathrm{T}}$ (=ATCC 35879, type strain), CCT 6753 (=ATCC 35881), grapevine (Vitis sp., Florida); and CCT 6747 (=ATCC 35871) hybrid plum (Prunus amygdallus, Georgia) $(\mathrm{CCT}=$ Coleção de Culturas Tropical, Campinas, SP, Brazil; and ATCC = American Type Culture Collection, Manassas, VA). Strains were grown in $5.0 \mathrm{ml}$ of PW broth (12; modified with $3.5 \mathrm{~g}$ instead of $6.0 \mathrm{~g}$ of bovine serum albumin fraction $\mathrm{V}$ per liter) in 18-mm-diameter glass culture tubes or in $25.0 \mathrm{ml}$ of $\mathrm{PW}$ broth in 125-ml Erlenmeyer flasks, with orbital agitation $120 \mathrm{rpm}$. Static cultures (no agitation applied) were also prepared in 18-mm-diameter glass tubes and maintained on a tube rack in vertical position. Cultures were incubated at room temperature $\left(20\right.$ to $\left.22^{\circ} \mathrm{C}\right)$ and transferred to fresh media every 1 to 2 weeks. Cultures maintained in tubes were transferred in a 1:10 ratio, while cultures in flasks were replicated in a 1:25 ratio. For evaluation of attachment to glass, cultures were grown in 
flasks and tubes for 14 to 30 days, with orbital agitation $120 \mathrm{rpm}$, and were visually observed every 3 days. Observations were confirmed in at least three different sets of experiments. Glass tubes were sectioned using a diamond cutter, and sections containing bacterial growth were removed for analysis by scanning microscopy. Clumping formation was evaluated by visual observation of static cultures grown for 14 days.

The ability to grow as biofilm in vitro was evaluated as follows. Pine wood sticks measuring $8.0 \mathrm{~cm}$ long $\times 0.6 \mathrm{~cm}$ wide $\times$ $0.1 \mathrm{~cm}$ thick, previously sterilized by autoclaving (20 $\mathrm{min}, 121^{\circ} \mathrm{C}$ ), were placed in the culture tubes containing the cultures. The tubes containing wood sticks were incubated under agitation in an orbital shaker, $120 \mathrm{rpm}$, at room temperature (20 to $22^{\circ} \mathrm{C}$ ). Wood sticks were removed for

Scanning electron microscopy. Wood sticks recovered from culture vessels were placed in a $15-\mathrm{ml}$ polypropylene tube and air-dried overnight. The material was fixed in $5 \%$ glutaraldehyde prepared in $0.1 \mathrm{M}$ sodium cacodylate buffer, $\mathrm{pH} 7.2$, overnight at $4^{\circ} \mathrm{C}$. After removal of fixative solution, the wood sticks were cut in four sections: bottom and top section for surface analysis and two cuts of the middle portion for analysis of internal surfaces of the wood vessels, one tangential longitudinal and one radial longitudinal. Wood sections measured approximately 1.0 to $1.5 \mathrm{~cm}$ in length. The cut pieces were then placed in sterile petri dishes and air-dried in a fume hood for 7 days. Sections of glass culture tubes containing bacterial growth attached to internal surfaces were cut with a glass dia$\mathrm{h}$ in the fixative solution (above) and airdried for a few hours at room temperature prior to analysis.

Wood and glass sections were assembled onto stubs and sputter-coated with goldpalladium. Scanning electron microscopy was performed by using a Cambridge microscopy analyses at day 30 . mond cutter. These samples were fixed for 1

Model 360 SEM at $10 \mathrm{Kv}$ emission. Digital images were captured from the SEM using OmniVision (v. 5.1) software and imported into Adobe Photoshop (Windows v. 6.0; Adobe Systems Incorporated, San Jose, CA) for storage and printing.

\section{RESULTS}

All strains of $X$. fastidiosa analyzed formed aggregates and biofilms under the experimental conditions. Growth of strains in glass tubes under static conditions often led to heavy clumping of cells, evident by direct visual observation, especially for the citrus and coffee strains. Citrus and coffee static cultures were usually clear, with no significant turbidity, but contained abundant clumps in suspension in the medium or deposited at the bottom of the culture tubes. Almond, elm, grape, and plum strains usually did not show visible clumping, and the cultures were turbid, more typical of planktonic growth. However, light-microscopy analysis showed that all strains tested formed clumps and microcolonies to some degree (data not shown). A summary of the properties of the strains regarding attachment to glass and wood surfaces, biofilm formation, and clumping is presented in Table 1 .

Growth of almond (CCT 6746), elm (CCT 6748), grape (CCT 6068 and CCT 6752), and plum (CCT 6747) strains of $X$. fastidiosa in flasks under orbital agitation led to the production of a "ring" of bacterial cells attached to the glass at the airmedium interface (Fig. 1A). For citrus and coffee strains, attachment to the surface of the glass was not observed, except for strain CCT 6740, where some growth was visible on the walls of culture vessels in the presence of wood. The growth rings started to be visible 1 to 3 days after inoculation for the grape strains, about 7 to 10 days for the almond strain, and about 14 days for the elm and plum strains. SEM of growth rings formed by grape strains confirmed them as biofilms based on the typical biofilm morphology, i.e., large aggre-

Table 1. In vitro formation of aggregates and biofilms by Xylella fastidiosa strains isolated from different host plants

\begin{tabular}{|c|c|c|c|c|c|}
\hline Strain $^{a}$ & Source host & Clumps $^{b}$ & $\begin{array}{c}\text { Strands of } \\
\text { cells }^{b}\end{array}$ & $\begin{array}{l}\text { Attachment } \\
\text { to glass }\end{array}$ & $\begin{array}{l}\text { Biofilm on } \\
\text { wood }\end{array}$ \\
\hline CCT 5598 & Citrus & $+++^{c}$ & + & 0 & +++ \\
\hline CCT 5641 & Citrus & +++ & 0 & 0 & + \\
\hline CCT 5643 & Citrus & +++ & 0 & 0 & + \\
\hline CCT 5674 & Citrus & +++ & + & 0 & ++ \\
\hline ССТ 6739 & Coffee & +++ & 0 & 0 & ++ \\
\hline ССТ 6740 & Coffee & +++ & 0 & 0 & ++ \\
\hline ССТ 6746 & Almond & + & ++ & +++ & +++ \\
\hline СCT 6747 & Plum & + & ++ & ++ & + \\
\hline СCT 6748 & Elm & + & ++ & ++ & +++ \\
\hline ССТ 6068 & Grapevine $^{\mathrm{d}}$ & ++ & ++ & +++ & +++ \\
\hline CCT $6752^{\mathrm{T}}$ & Grapevine $^{\mathrm{d}}$ & ++ & +++ & +++ & +++ \\
\hline ССТ 6753 & Grapevine $^{\mathrm{d}}$ & + & ++ & 0 & ++ \\
\hline
\end{tabular}

a $\mathrm{T}=$ type strain.

${ }^{\mathrm{b}}$ Growth in liquid culture (PW broth) in absence of wood sticks.

${ }^{c}$ Frequency of occurrence and size: $0=$ absent, $+=$ low, $++=$ moderate, $+++=$ high.

${ }^{\mathrm{d}}$ Late development (6 to 12 weeks to form visible aggregates). gates of cells surrounded by abundant exopolymeric matrix (Fig. 1B).

A new model system to investigate in vitro biofilm formation by $X$. fastidiosa was devised, using wooden sticks as an attachment surface. All $X$. fastidiosa strains tested in this study, including strains from almond, citrus, coffee, elm, grape, and plum, formed biofilms on the wood supports. Large aggregates of cells embedded in an exopolymeric matrix were found attached to all sections of the wood sticks by the SEM analyses. The different sections included: (i) the bottom portion of the stick, immersed in the culture medium; (ii) the top portion of the stick, soaked with culture medium by capillary action and exposed to the air interface; and portions in the middle of the stick, analyzed by (iii) radial longitudinal cuts, to expose the internal surface of xylem vessels, and (iv) tangential cuts, assembled with the internal side up, exposing the vessels from a different angle. In general, biofilms were more abundant close to the culture medium-air interface and on the portions of the sticks not immersed in the media, particularly on sections (ii) (wood-air interface, external surface) and (iv) (tangential cuts, internal surface) described above.

The grape strain CCT $6752^{\mathrm{T}}$ formed thick and large biofilms (over $400 \mu \mathrm{m}$ in length and/or width) on external surfaces of the bottom section of the wood stick (Fig. 2B). Biofilms were composed of elongated cells tightly attached to each other, immersed in an abundant exopolymeric matrix, organized mostly in tandem and forming varied sizes of intertwined filaments where individual cells were often indistinguishable.

The bacteria invaded the internal xylem vessels of the wood sticks, forming large biofilms (over $300 \mu \mathrm{m}$ in length and/or width). For strains CCT 6746 (almond) (Fig. 2D) and CCT 6748 (elm) (not shown), biofilms growing in the vessels showed elongated cells crowded in large multilayer aggregates, organized in parallel, palisades or in tandem. These same strains yielded large, thick biofilms at the wood-air interface at the top of the sticks, where cells were smaller and organized similarly to biofilms formed by citrus and coffee strains (Fig. 2A and C).

The citrus and coffee strains presented a slightly different biofilm organization. Cells were more dispersed and usually surrounded by copious amounts of exopolymeric matrix secreted by individual cells or small groups of cells starting at early stages of biofilm development (Fig. 2A). Elongated cells or long filaments of cells were not often observed for these cultures. The plum strain CCT 6747 analyzed in this study formed large biofilms with very tiny cells, especially at the wood-air interface surface (Fig. 2E).

Biofilms at different stages of development were also detected in the same sam- 
ples. For example, growth of the grape strain CCT $6752^{\mathrm{T}}$ could be seen in the form of isolated cells attached to the wood, cells starting to pair up side by side, and cells organized in filaments (data not shown). At the same time, patches of cells tightly attached to each other and multilayers could be observed in different sections of the wood, and large masses of multilayer cell aggregates could be seen covering extensive areas of the wood's surface. Copious amounts of exopolymeric matrix were associated with these larger biofilms (Fig. 2B).

In addition, time course studies of the grape strains CCT 6068 and CCT 6752 were carried out at $4,11,16$, and 30 days of cultivation in glass tubes. Independent wood sticks, started from the same inoculum, were sampled for each strain at the specific time periods. There was no significant biofilm formation at day 4 , although occasional isolated cells and microcolonies were observed attached to the wood surface for strain CCT 6752. At day 11, strain CCT 6752 had developed thick biofilms and strain CCT 6068 was starting to develop larger cell aggregates. At day 16, CCT 6068 presented thicker biofilms, while not much difference could be detected for strain CCT 6752 in comparison to day 11. Biofilms observed at day 30 were described in detail above.

\section{DISCUSSION}

The results demonstrated that $X$. fastidiosa is indeed a biofilm-forming plantpathogenic bacterium, and that biofilm and multicellular behavior is pervasive among strains from various host plants. These data correlate with previous transmission and scanning electron microscopy images (TEM and SEM) of the bacterium growing in the plant xylem and insect foregut, showing large aggregates of cells embedded in an electron-dense material $(1,16,18$, $23,34)$ and descriptions of "bacterial masses" in plant tissues and "carpet-like mats of bacterial cells" adhered to insects' foreguts (30). Hopkins (17) described the formation of bacterial aggregates that appear to be held together by fibrous strands resembling and functioning as a glycocalyx, and describes the formation of microcolonies in the plant vessels by grape strains of $X$. fastidiosa. In his classical review on $X$. fastidiosa, Hopkins (17) reported: "...serial subculturing of these strains results in the loss of the aggregation characteristic and of virulence...", suggesting a connection between aggregation and virulence, or aggressiveness. However, no formal characterization of biofilms formed by $X$. fastidiosa has been previously reported, either in vivo or in vitro.

Large microbial biofilms have been previously associated with external plant surfaces $(14,15,24,25,31)$. Although there have been no specific reports of biofilm development in the plant vessels, disease symptoms associated with clogging of xylem vessels by large bacterial aggregates and abundant EPS production, the main components of biofilms, have been described $(13,17,21)$. Biofilm formation by plant-pathogenic microorganisms and its relation to the disease process have yet to be explored.

To the authors' knowledge, this is the first description of $X$. fastidiosa biofilm formation in vitro. We propose that biofilm formation is likely to be a key factor in the virulence of $X$. fastidiosa to plants, having a decisive role in the mechanical occlusion of xylem vessels. This phenomenon is directly related to most of the symptoms reported on several diseases associated with the presence of $X$. fastidiosa. Biofilm formation could also be involved in the colonization of insect vector's foregut (1) and in enhancing the likelihood of bacterial transmission by insects by maintaining large numbers of cells concentrated in aggregates. In addition, biofilms may play an important role in cell-density-dependent regulation of virulence. Therefore, prevention of biofilm formation or disruption of these biofilms could be an effective approach to reducing or controlling diseases caused by $X$. fastidiosa.

In this study, we developed a relatively fast and simple in vitro model to study $X$.
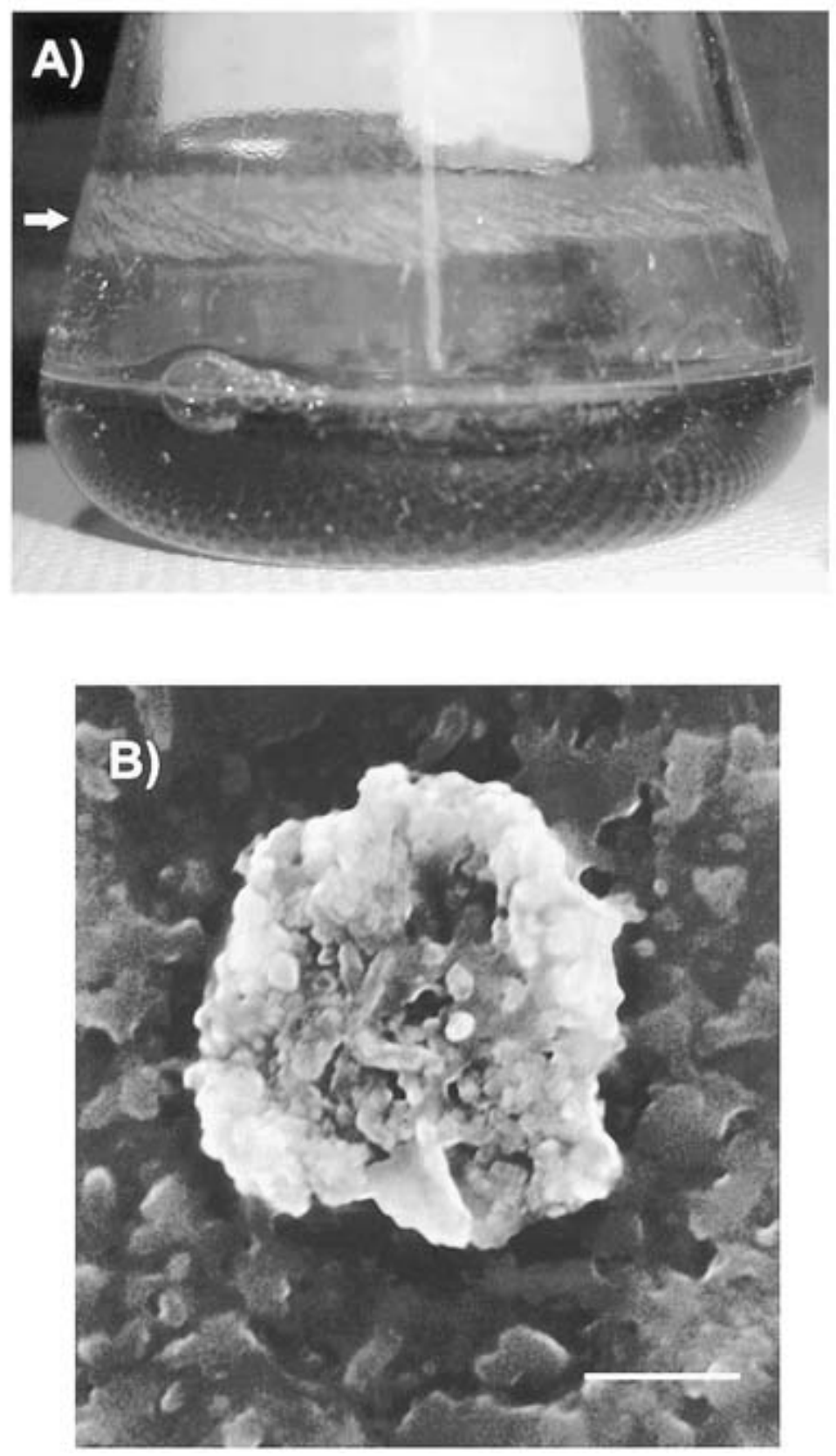

Fig. 1. A, Biofilm formed at the liquid-air interface (arrow) by a grape strain of Xylella fastidiosa, CCT $6752^{\mathrm{T}}$, representing biofilms attached to glass as observed for almond, elm, grape, and plum strains. B, Scanning electron micrograph of biofilms formed by $X$. fastidiosa grape strain CCT $6752^{\mathrm{T}}$ on the glass surface of $18-\mathrm{mm}$ culture tubes. The bacteria are present within a microcolony as well as distributed over the glass surface (background) encased in a thick polymeric matrix. Bar $=5.0 \mu \mathrm{m}$. 
fastidiosa biofilm formation. Methods for studying biofilms have flourished in the past decade $(2,3,11,27)$, mostly for clinically important bacterial species. The vast array of niches and life styles presented by microbes in nature may avert the application of a universal model to study biofilm formation, creating great potential for the development of new, optimized models customized for particular microorganisms. We reasoned that by using wood, which is rich in secondary xylem, $X$. fastidiosa would be provided with a surface that closely mimics one of its natural habitats, the plant xylem. The SEM results showed that this model was very effective in promoting biofilm formation by $X$. fastidiosa strains isolated from a range of host plant species.

This model was very useful in the characterization of biofilms formed by various $X$. fastidiosa strains. Differences in biofilm morphology were observed between the strains and for the same strain, grown under the same conditions, with two main morphological types of biofilms detected on the inoculated wood: blunt and filamentous (Fig. 2). The almond and grape strains presented both biofilm morphotypes growing on the same wood stick. It is quite likely that the pleiomorphism displayed by these strains was due to microenvironmental variations at distinct areas of the wooden sticks (i.e., outer/inner surfaces of vessels, liquid/wood-air interface, differences in shear force, nutrient availability). Variation in biofilm formation due to micro-environmental conditions has been reported for other bacteria. Danese et al. (10) demonstrated that Escherichia coli formed morphologically and molecularly distinct biofilms under various growth conditions, and it has been shown that Pseudomonas fluorescens presents multiple genetic pathways that control biofilm development under different environments (27). Therefore, it is likely that the occurrence of distinct biofilm morphotypes formed by the same $X$. fastidiosa strain reflects the expression of different genes or sets of genes under diverse microenvironmental conditions, which could reveal distinct genetic pathways that could be targeted for biofilm disruption.

The differences in biofilm morphology observed between different strains of $X$. fastidiosa revealed their grouping in at least two distinct clusters, which is supported by variation of other features, such as aggregative behavior in liquid culture and ability to attach to different surfaces. Citrus and coffee strains could be allocated to one group, showing pronounced formation of clumps in static culture, no attachment to glass, and a weaker tendency overall for the formation of extensive and/or
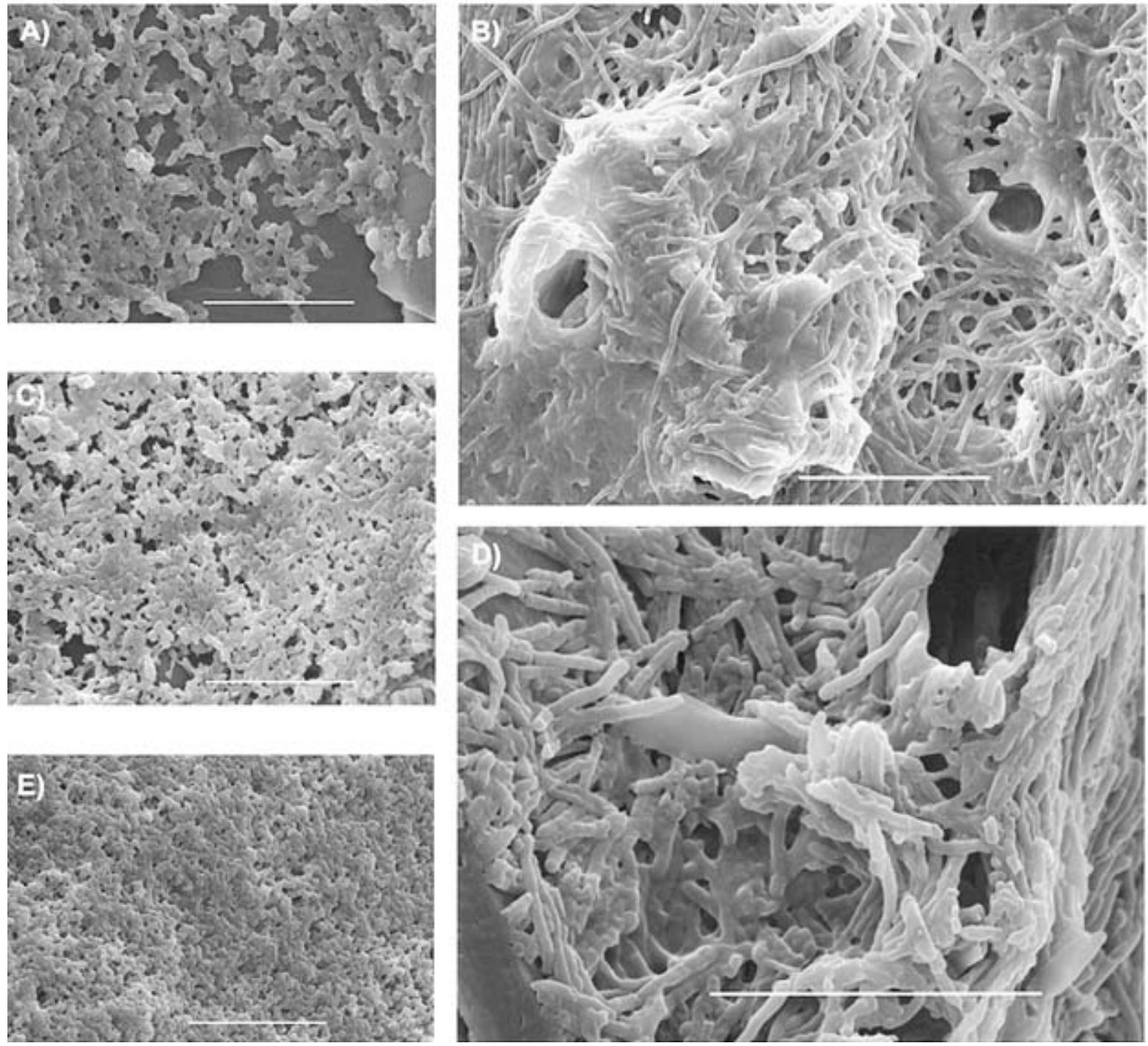

Fig. 2. Biofilm formation by Xylella fastidiosa strains on wood. A, CCT 5598 (citrus) biofilm on wood external surface, at the wood-air interface, representative of biofilms formed by citrus and coffee strains; B, CCT $6752^{\mathrm{T}}$ (grape) biofilm formed on the external surface of wood immersed in media; C, CCT 6068 (grape), representative of biofilms formed by most strains at the external top portion of the wood stick, at the wood-air interface; D, CCT 6746 (almond), biofilm formed on an internal surface of the wooden stick, exposed by tangential cut, similar to biofilms formed by elm and grape strains; E, CCT 6747 (plum) biofilm, comprised of smaller cells, on the external surface at the wood-air interface. Note the filamentous morphotypes in B and D. Bar $=10.0 \mu \mathrm{m}$. 
abundant biofilms under the conditions tested in these experiments, with the exception of citrus strain CCT 5598. In addition, citrus and coffee strains displayed just one type of biofilm morphology on the wood stick. On the other hand, in general, almond, elm, and grape strains presented less pronounced or microscopic clump formation in liquid culture, notable attachment to glass, and abundant biofilm formation on wood, with the exception of grape strain CCT 6753 (Table 1). Almond and grape strains showed pleiomorphic biofilms growing on the same wooden stick, as mentioned above. Therefore, two major groups could be defined, one encompassing citrus and coffee strains, or the CVC group; and the second including almond, elm, and grape strains, the Pierce's disease (PD) group. These groupings correlate with phylogenetic studies based on various molecular taxonomy techniques $(4,5,19,22,29)$. The plum strain was similar to the PD group in relation to clumping and attachment to surfaces, whereas its biofilm morphology was closer to that of the CVC group. Strains from elm and plum have been previously grouped together (4,5,29), whereas Metha and Rosato (22) grouped plum strains in the CVC group.

At this time, the use of different groups of strains in the various studies reported and the availability of a limited number of strains in service culture collections for taxonomic and molecular analysis have prevented a broader and more definite conclusion on $X$. fastidiosa infraspecific diversity and phylogeny. However, the differences in biofilm morphology on wood and differential attachment to various surfaces observed between the two major groups of strains suggest possible selection for adaptations to particular hosts. A better characterization of the biofilm behavior of strains from different clusters might be important in designing specific strategies to prevent and/or treat various $X$. fastidiosa infections.

Finally, the ability to attach to different surfaces presented by strains that attached to glass and wood is similar to what happens in nature, where $X$. fastidiosa strains adhere to the plant xylem and insect foregut (30), possibly reflecting the expression of diverse genes associated with adhesion. This is supported by genomic analysis of $X$. fastidiosa 9a5c, a CVC-associated strain, revealing multiple sequences related to adhesion $(20,33)$. Distinct bacterial molecules may be expressed for attachment to a particular surface or triggered under different micro-environmental conditions, which has been reported for other organisms $(11,26)$. The identification of such genes and molecules could reveal promising targets for treatment of $X$. fastidiosa diseases, preventing attachment and therefore biofilm development in the plant vessel and/or insect's foregut, or dislodgment of biofilms formed in infected plants.
In conclusion, we demonstrated that $X$. fastidiosa infections in plants are very likely biofilm diseases. The exact correlation between biofilm formation and pathogenicity in $X$. fastidiosa infections needs to be validated through further investigation. The identification and characterization of unique gene products expressed in $X$. fastidiosa biofilms is necessary to confirm that the biofilm phenotype is directly involved in the infection and development of the disease.

$X$. fastidiosa has the potential of becoming a natural model to study plant biofilm infections, similarly to what has occurred with Pseudomonas aeruginosa, the classical model in animal and human biofilm infections $(7,9)$. The recognition of the biofilm concept in plant pathology is likely to have profound impact in the field, as it had in medical microbiology, with vast implications in the development of novel strategies to prevent and eliminate these and other plant biofilm diseases.

\section{ACKNOWLEDGMENTS}

We thank Liz Middlemiss and Jonathan McGovern for valuable technical assistance with electron microscopy. This research was supported by the Natural Science and Engineering Research Council of Canada (M. E. Olson, H. Ceri, and D. M. Reid), the ASRA/Westain Chair in Biofilm Research (M. E. Olson), and FAPESP (G. Manfio). L. Marques is the recipient of University Technology International Inc. postdoctoral fellowship.

\section{LITERATURE CITED}

1. Brlansky, R. H., Timmer, L. W., French, W. J. and McCoy, R. E. 1983. Colonization of the sharpshooter vectors, Oncometopia nigricans and Homalodisca coagulata, by xylemlimited bacteria. Phytopathology 73:530-535.

2. Ceri, H., Olson, M., Morck, D., Storey, D., Read, R., Buret, A., and Olson, B. 2001. The MBEC Assay System: Multiple equivalent biofilms for antibiotic and biocide susceptibility. Methods Enzymol. 337:377-384.

3. Ceri, H., Olson, M. E., Stremick, C., Read, R. R., Morck, D., and Buret, A. 1999. The Calgary Biofilm Device: A new technology for the rapid determination of antibiotic susceptibility of bacterial biofilms. J. Clin. Microbiol. 37:1771-1776.

4. Chen, J., Chang, C. J., Jarret, R. L., and Gawel, N. 1992. Genetic variation among $X y$ lella fastidiosa strains. Phytopathology 82:973-977.

5. Chen, J., Jarret, R. L., Qin, X., Hartung, J. S., Banks, D., Chang, C. J., and Hopkins, D. L. 2000. 16S rDNA sequence analysis of Xylella fastidiosa strains. Syst. Appl. Microbiol. 23:349-354.

6. Chou, F. L., Chou, H. C., Lin, Y. S., Yang, B. Y., Lin, N. T., Weng, S. F., and Tseng, Y. H. 1997. The Xanthomonas campestris gumD gene required for synthesis of xanthan gum is involved in normal pigmentation and virulence in causing black rot. Biochem. Biophys. Res. Commun. 233:265-269.

7. Costerton, J. W. 2001. Cystic fibrosis pathogenesis and the role of biofilms in persistent infection. Trends Microbiol. 9:50-52.

8. Costerton, J. W., Lewandowski, Z., Caldwell, D. E., Korber, D. R., and Lappin-Scott, H. M. 1995. Microbial Biofilms. Annu. Rev. Microbiol. 49:711-745.

9. Costerton, J. W., Stewart, P. S., and Greenberg, E. P. 1999. Bacterial biofilms: A com- mon cause of persistent infections. Science 284:1318-1322.

10. Danese, P. N., Pratt, L. A., Dove, S., and Kolter, R. 2000. The outer membrane protein, antigen 43, mediates cell-to-cell interactions within Escherichia coli biofilms. Mol. Microbiol. 37:424-432.

11. Danese, P. N., Pratt, L. A., and Kolter, R. 2001. Biofilm formation as a developmental process. Methods Enzymol. 336:19-26.

12. Davis, M. J., French, W. J., and Schaad, N. W. 1981. Axenic culture of the bacteria associated with phony disease of peach and plum leaf scald. Curr. Microbiol. 6:309-314.

13. Denny, T. P. 1995. Involvement of bacterial polysaccharides in plant pathogenesis. Annu. Rev. Phytopathol. 33:173-197.

14. Fett, W. F. 2000. Naturally occurring biofilms on alfalfa and other types of sprouts. J. Food Prot. 63:625-632

15. Fuqua, C., and Matthysse, A. G. 2001. Methods for studying bacterial biofilms associated with plants. Methods Enzymol. 337:3-18.

16. Hearon, S. S., Sherald, J. L., and Kostka, S. J. 1980. Association of xylem-limited bacteria with elm, sycamore, and oak leaf scorch. Can. J. Bot. 58:1986-1993.

17. Hopkins, D. L. 1989. Xylella fastidiosa: A xylem-limited bacterial pathogen of plants. Annu. Rev. Phytopathol. 27:271-290.

18. Huang, P.-Y., Milholland, R. D., and Daykin, M. E. 1986. Structural and morphological changes associated with the Pierce's disease bacterium in bunch and muscadine grape tissues. Phytopathology 76:1232-1238.

19. Kamper, S. M., French, W. J., and DeKloet, S. R. 1985. Genetic relationships of some fastidious xylem-limited bacteria. Int. J. Syst. Bacteriol. 35:185-188.

20. Lambais, M. R., Goldman, M. H. S. Camargo, L. E. A., and Goldman, G. H. 2000. A genomic approach to the understanding of Xylella fastidiosa pathogenicity. Curr. Opin. Microbiol. 3:459-462.

21. Leigh, J. A., and Coplin, D. L. 1992. Exopolysaccharides in plant-microbe interactions. Annu. Rev. Microbiol. 46:307-346.

22. Metha, A., and Rosato, Y. B. 2001. Phylogenetic relationships of Xylella fastidiosa strains from different hosts, based on 16S rDNA and 16S-23S intergenic spacer sequences. Int. J Syst. Evol. Microbiol. 51:311-318.

23. Mollenhauer, H. H., and Hopkins, D. L. 1974 Ultrastructural study of Pierce's disease bacterium in grape xylem tissue. J. Bacteriol. 119:612-618.

24. Morris, C. E., Monier, J. M., and Jacques, M. A. 1997. Methods for observing microbial biofilms directly on leaf surfaces and recovering them for isolation of culturable microrganisms. Appl. Environ. Microbiol. 63:15701576.

25. Morris, C. E., Monier, J. M., and Jacques, M. A. 1998. A technique to quantify the population size and composition of the biofilm component in communities of bacteria in the phyllosphere. Appl. Environ. Microbiol. 64:47894795.

26. O'Toole, G., Kaplan, H. B., and Kolter, R. 2000. Biofilm formation as microbial development. Annu. Rev. Microbiol. 54:49-79.

27. O'Toole, G. A., and Kolter, R. 1998. Initiation of biofilm formation in Pseudomonas fluores cens WCS365 proceeds via multiple, convergent signalling pathways: A genetic analysis. Mol. Microbiol. 28:449-61.

28. Pierson III, L. S., Wood, D. W., and Pierson, E. A. 1998. Homoserine lactone-mediated gene regulation in plant-associated bacteria. Annu. Rev. Phytopathol. 36:207-225.

29. Pooler, M. R., and Hartung, J. S. 1995. Specific PCR detection and identification of $X y$ lella fastidiosa strains causing citrus varie- 
gated chlorosis. Curr. Microbiol. 31:377-381.

30. Purcell, A. H., and Hopkins, D. L. 1996. Fastidious xylem-limited bacterial plant pathogens. Annu. Rev. Phytopathol. 34:131151.

31. Seo, K. J., and Frank, J. F. 1999. Attachment of Escherichia coli $\mathrm{O} 157: \mathrm{H} 7$ to lettuce leaf surface and bacterial viability in response to chlorine treatment as demonstrated by using confocal scanning laser microscopy. J. Food Prot. 62:3-9.

32. Silva, F. R., Vettore, A. L., Kemper, E. L.,
Leite, A., and Arruda, P. 2001. Fastidian gum: The Xylella fastidiosa exopolysaccharide possibly involved in bacterial pathogenicity. FEMS Microbiol. Lett. 203:165-171.

33. Simpson, A. J. G., Reinach, F. C., Arruda, P., Abreu, F. A., Acencio, M., Alvarenga, R., Alves, L. M. C., Araya, J. E., Baia, G. S., Baptista C. S., et al. 2000. The genome sequence of the plant pathogen Xylella fastidiosa. Nature 406:151-159.

34. Stencel, C. 2000. New vector's invasion threatens California's chief cash crop. ASM
News 66:328-329.

35. Tyson, G. E., Stojanovic, B. J., Kuklinski, R. F., DiVittorio, T. J., and Sullivan, M. L. 1985 Scanning electron microscopy of Pierce's disease bacterium in petiolar xylem of grape leaves. Phytopathology 75:264-269.

36. Wells, J. M., Raju, B. C., Hung, H.-Y., Weisberg, W. G., Mandelco-Paul, L., and Brenner, D. J. 1987. Xylella fastidiosa gen. nov., sp. nov.: Gram-negative, xylem-limited, fastidious plant bacteria related to Xanthomonas spp. Int. J. Syst. Bacteriol. 37:136-143. 